\title{
Article \\ Synthesis of Porous Biomimetic Composites: A Sea Urchin Skeleton Used as a Template
}

\author{
Nikolay P. Shapkin ${ }^{1, *}$, Evgeniy K. Papynov ${ }^{1,2}{ }^{\oplus}$, Alexandr E. Panasenko ${ }^{2}$, Irina G. Khalchenko ${ }^{1}$, \\ Vitaly Yu. Mayorov ${ }^{2}\left(\mathbb{D}\right.$, Anatoliy L. Drozdov ${ }^{3}$, Natalya V. Maslova ${ }^{1}$ and Igor Yu. Buravlev ${ }^{1,2}{ }^{\mathbb{D}}$ \\ 1 FEFU Campus, Far Eastern Federal University, 10 Ajax Bay, Russky Is., 690922 Vladivostok, Russia; \\ papynov@mail.ru (E.K.P.); khalch@mail.ru (I.G.K.); maslova.nv@dvfu.ru (N.V.M.); \\ buravlev.i@gmail.com (I.Y.B.) \\ 2 Institute of Chemistry, Far Eastern Branch of Russian Academy of Sciences, Prospect 100-let Vladivostoku, \\ 159, 690922 Vladivostok, Russia; panasenko@ich.dvo.ru (A.E.P.); 024205@inbox.ru (V.Y.M.) \\ 3 National Scientific Center for Marine Biology Named after V.I. A.V. Zhirmunsky Far Eastern Branch of \\ Russian Academy of Sciences, St. 17 Palchevsky, 690041 Vladivostok, Russia; anatoliyld@mail.ru \\ * Correspondence: npshapkin@gmail.com
}

\section{check for} updates

Citation: Shapkin, N.P.; Papynov, E.K.; Panasenko, A.E.; Khalchenko, I.G.; Mayorov, V.Y.; Drozdov, A.L.; Maslova, N.V.; Buravlev, I.Y. Synthesis of Porous Biomimetic Composites: A Sea Urchin Skeleton Used as a Template. Appl. Sci. 2021, 11, 8897. https:// doi.org/10.3390/app11198897

Academic Editor: Fernandez Velasco Leticia

Received: 30 August 2021

Accepted: 13 September 2021

Published: 24 September 2021

Publisher's Note: MDPI stays neutral with regard to jurisdictional claims in published maps and institutional affiliations.

Copyright: (c) 2021 by the authors. Licensee MDPI, Basel, Switzerland. This article is an open access article distributed under the terms and conditions of the Creative Commons Attribution (CC BY) license (https:// creativecommons.org/licenses/by/ $4.0 /)$.

\begin{abstract}
The paper presents an original method for the template synthesis of biomimetic porous composites using polyferrophenylsiloxane (PFPS) and the skeleton of the sea urchin Strongylocentrotus intermedius as a structuring template. The study aimed to form an organosilicon base of a composite with an inverted structure relative to the original structure of the sea urchin shell with a period of structure movement of about $20 \mu \mathrm{m}$ and ceramic composites fabrication with the silicate base with an average pore size distribution of about $10 \mu \mathrm{m}$ obtained by the reaction of PFPS with the inorganic base of the sea urchin test under conditions of calcination at $1000{ }^{\circ} \mathrm{C}$ followed by acid etching. The composition and morphology of the obtained composites were investigated by IR, XRD, XPS, EDX, and SEM techniques and by mercury porosimetry; the parameters of the porous structures depend on the selected methods of their synthesis. The proposed method is of fundamental importance for developing methods for the chemical synthesis of new biomimetics with a unique porosity architecture based on environmentally friendly natural raw materials for a vast practical application.
\end{abstract}

Keywords: biomimetic materials; ceramic composites; sea urchin skeleton; calcium silicate; polymerorganic compounds; template synthesis

\section{Introduction}

Synthetic materials that mimic biological systems' structural and functional properties represent a class of biomimetic materials included in modern materials science. The methods of their production determine the level of technological progress in the creation of new generation materials. Biomimetic materials demonstrate excellent properties as optical [1] and electrochemical [2] sensors, anodic materials for $\mathrm{Li}$-ion batteries [3], corrosion-resistant products [4], triboelectric nanogenerators [5], and other engineering devices [6]. Additionally, these materials proved their indisputable advantage for the tasks of biomedicine as biomaterials for regeneration of bones [7] and skin tissues [8], as drug delivery agents [9], antibacterial systems [10], antioxidants [11], etc.

A separate important area of biomimetics application is the technology of membrane and filtration purification of liquid [12,13] and gaseous media [14,15] from various pollutants: heavy metals, organic substances, combustion products, or radioactive components. In these processes, biomimetic materials characterized by such fundamental properties as the permeability and permeability of liquid or gas flows through their volume and the ability to include functionally active surface centers. The properties of these membranes and filters that absorb pollutants are determined mainly by the structure and composition of biomimetic components. Purification of components occurs through physicochemical 
processes, including the effects of molecular sieving through the pores and specific chemical interactions between the pore surface and the solute. A recent review by Tu et al. [16] presents their studies that show that the characteristics of porosity (type of pores, pore size distribution, pore density, aperture) are the key factors that determine the efficiency of biomimetic membranes for various applications. Interestingly, the structural parameters of the materials are also crucial for electrochemical applications [17-19].

These functional structures with the required transport pores are created based on template synthesis using inorganic and polymer patterns (templates) that form a porous framework [20,21]. The sea urchin test, which is an organic-inorganic biocomposite, is of great interest as such a template. As shown in the skeletons of the sea urchins Heterocentrotus mamillatus [22] and Strongylocentrotus intermedius [23], these skeletons are characterized by their complex bicontinuous porous structure, also known as stereome, which often also exhibits controlled gradients of porosity and structural change [24]. At the same time, individual skeletons based on stereomes are single crystals based on calcite containing magnesium [23,25], which indicates the chemical activity of the inorganic base of the sea urchin skeleton when used as a raw material in chemical synthesis.

Considering the possibilities of chemical and biochemical application of the sea urchin skeletons to create new functional materials, we investigated the chemical interaction of organosiloxans with the sea urchin skeleton as a pore-forming template for obtaining new materials with a developed porous structure. The method proposed in this work can be of fundamental importance for determining the possibility of obtaining ordered porous composite materials for a vast practical application, including technologically demanded highly porous cellular membranes or filters.

\section{Materials and Methods}

\subsection{Reagents}

The skeleton of the sea urchin Strongylocentrotus intermediateus (Sea of Japan) was used as a template for porous ceramic frame formation. Polyferrophenylsiloxane (PFPS) and $\mathrm{FeCl}_{3} \cdot 6 \mathrm{H}_{2} \mathrm{O}(99.98 \%$ purity) were used as a precursor for the fabrication of composites. Dimethylsulfoxide (DMSO) and toluene were used as solvents.

\subsection{Methods of Synthesis}

\subsubsection{Synthesis of PFPS}

Synthesis of PFPS was carried out according to the previously developed methods [26]. A mixture of $27.0 \mathrm{~g} \mathrm{FeCl} \cdot 6 \mathrm{H}_{2} \mathrm{O}(0.1 \mathrm{M})$ and $94 \mathrm{~g}$ of DMSO dissolved in $150 \mathrm{~mL}$ of toluene was boiled until complete water evaporation in the Dean-Stark trap. A solution of $58.8 \mathrm{~g}$ $(0.3 \mathrm{M}) \mathrm{C}_{6} \mathrm{H}_{5} \mathrm{Si}(\mathrm{OH})_{2} \mathrm{ONaH}_{2} \mathrm{O}$ in $50 \mathrm{~mL}$ of toluene and $48 \mathrm{~g}$ of DMSO was added to the resulting suspension. The yield of the target polymer product was $90.0 \mathrm{wt} \%$.

\subsubsection{Synthesis of the PFPS-Based Composite}

Synthesis of the PFPS-based composite was carried out by impregnating of $10 \mathrm{~g}$ the sea urchin skeleton (fraction of $2-8 \mathrm{~mm}$ ) with $25 \mathrm{~mL}$ of a $5 \%$ solution of PFPS in toluene in vacuum media (50-100 mm Hg); the obtained sample was dried in air at $60{ }^{\circ} \mathrm{C}$. The impregnation was performed twice with the use of this technique. The resulting sample was then treated with a $2 \% \mathrm{HCl}$ solution until the urchin skeleton was dissolved entirely (sample "c-PFPS"). Additionally, composite No.1 was calcinated at $1000{ }^{\circ} \mathrm{C}$ ("c-PFPS/1000") and acid-treated with $2 \% \mathrm{HCl}$ ("c-PFPS/1000/ $\mathrm{HCl}^{\prime \prime}$ ) (see Table 1).

\subsection{Characterization of Research Methods}

The IR spectra of the polymer samples were recorded using a Spectrum-1000 Fourier transform spectrometer "PerkinElmer" (Waltham, MA, USA) with $\mathrm{KBr}$ tablets. X-ray diffraction analysis (XRD) was carried out on a D8 Advance "Bruker" diffractometer (Karlsruhe, Germany) using Cu-Ka irradiation in the angle range $2^{\circ}<2 \Theta^{\circ}<90^{\circ}$. The maximum deviation of the reflex position according to NIST SRM 1976 was less than 
$0.01^{\circ} 2 \Theta$. The morphology of the samples was investigated using a scanning electron microscope (SEM) EVO 40 "Carl Zeiss" (Oberkochen, Germany) and a BX-43 "Olympus" optical microscope (Tokyo, Japan) with an XC-50 "Olympus" camera. Elemental analysis (XPS) of dried and original sea urchin samples was carried out using an X-ray fluorescence spectrometer EDX 800 HS "Shimadzu" (Kyoto, Japan). SEM was performed on a CrossBeam 1540 XB "Carl Zeiss" (Oberkochen, Germany) equipped with the add-on set for energydispersive X-ray spectral analysis (EDX) "Bruker" (Billerica, MA, USA). The carbon content of the samples was determined by the wet combustion method.

Table 1. List of samples and conditions for the composite synthesis.

\begin{tabular}{ccccc}
\hline No. & Sample & $\begin{array}{c}\text { Impregnation } \\
\text { with Polymer }\end{array}$ & $\begin{array}{c}\text { Calcination after } \\
\text { Impregnation } \\
\text { with Polymer }\end{array}$ & $\begin{array}{c}\text { Acid Treatment } \\
\text { after Calcination }\end{array}$ \\
\hline 1 & C-PFPS & PFPS & - & - \\
2 & c-PFPS $/ 1000$ & PFPS & $1000^{\circ} \mathrm{C}$ & - \\
3 & c-PFPS $/ 1000 / \mathrm{HCl}$ & PFPS & $1000^{\circ} \mathrm{C}$ & $\mathrm{HCl}$ \\
\hline
\end{tabular}

\section{Results}

The XPS analysis (Table 2) showed that the skeleton of the gray sea urchin (stereome) consists of calcite $\left(\mathrm{CaCO}_{3}\right)$ in composition with magnesium in the form of magnesite $\left(\mathrm{MgCO}_{3}\right)$.

Table 2. Elemental composition of the skeleton of the gray sea urchin Strongylocentrotus intermedius before and after calcination (XPS analysis).

\begin{tabular}{ccccccccc}
\hline \multirow{2}{*}{ Object } & \multicolumn{7}{c}{ Content of Elements, wt\% * } \\
\cline { 2 - 8 } & $\mathbf{C a O}$ & $\mathbf{M g O}$ & $\mathbf{N a}_{\mathbf{2}} \mathbf{O}$ & $\mathbf{K}_{\mathbf{2}} \mathbf{O}$ & $\mathbf{S i O}_{\mathbf{2}}$ & $\mathbf{P}_{\mathbf{2}} \mathbf{O}_{\mathbf{5}}$ & $\mathbf{S r O}$ & $\mathbf{F e}_{\mathbf{2}} \mathbf{O}_{\mathbf{3}}$ \\
\hline Test of the sea urchin (original) & 45.98 & 11.03 & 40.70 & 1.52 & 0.30 & - & 0.20 & 0.11 \\
Test of the urchin (calcined at $700{ }^{\circ} \mathrm{C}$ ) & 87.40 & 11.67 & - & - & - & - & 0.46 & 0.11 \\
\hline
\end{tabular}

${ }^{*}$ Note: XPS method error is no more than $0.3 \mathrm{wt} \%$.

XRD and IR-spectroscopy showed that the sea urchin skeleton is formed by highmagnesium solid calcite (Figures 1 and 2).

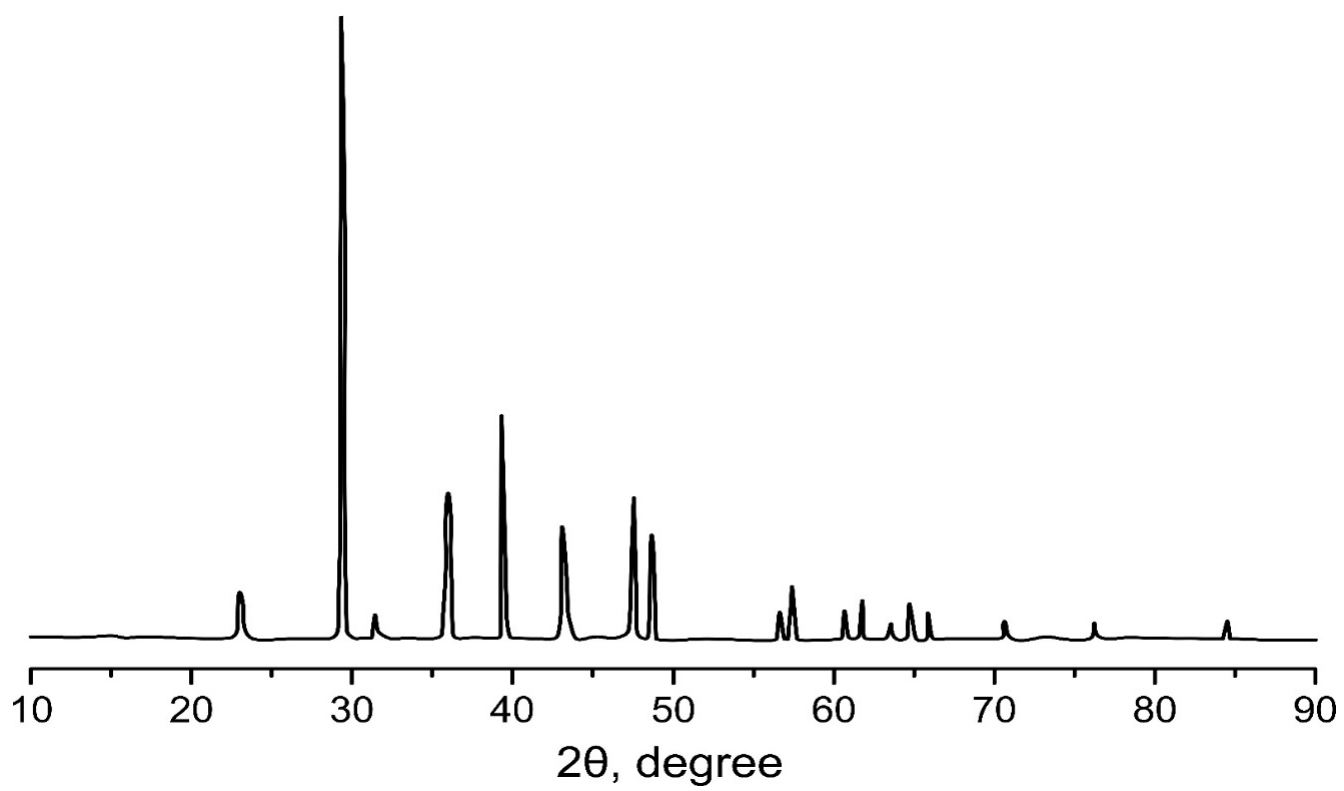

Figure 1. XRD of the original shell of the gray sea urchin Strongylocentrotus intermedius. 


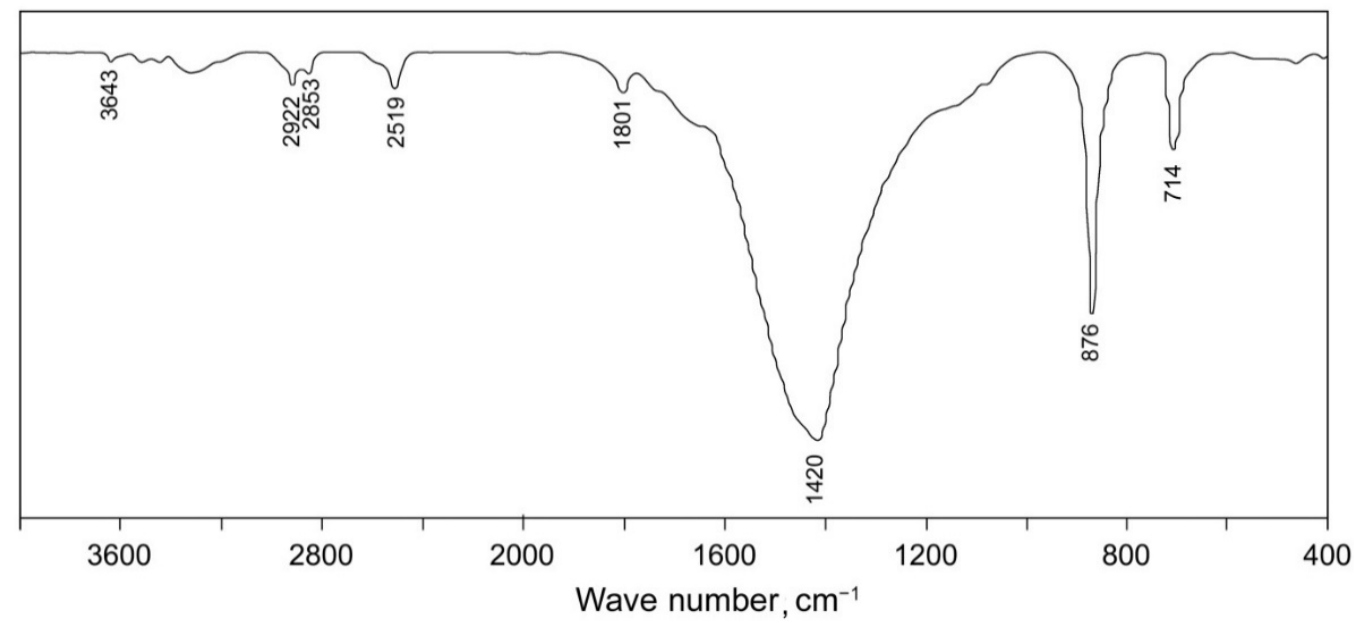

Figure 2. IR spectrum of the original shell of the gray sea urchin Strongylocentrotus intermedius.

The FTIR spectra of the shell of sea urchins (Figure 2) have a distinct absorption band at about $1430-1410 \mathrm{~cm}^{-1}$, which refers to the asymmetric stretching vibration of the C-O bond in the $\mathrm{CO}_{3}{ }^{2-}$ group in calcite, as well as weak in the intensity of absorption bands located at 2910 and $2880 \mathrm{~cm}^{-1}$, related to stretching vibrations of the $\mathrm{C}-\mathrm{H}$ bond, indicating the presence of organic matter.

The gray sea urchin is covered with short spines of different numerous color variations: purple with brown tips, white and violet-white, dark green with a purple or red top, brown, and light green. The test with removed spines consists of plates with holes for ambulacral feet and attachment points for movable spines. A spongy or cellular stereome represents the skeleton of the shell. The pore spaces in the points of removed spines are connected into a single system, which can account for up to half of the total skeleton volume (Figure $3 a, b$ ).
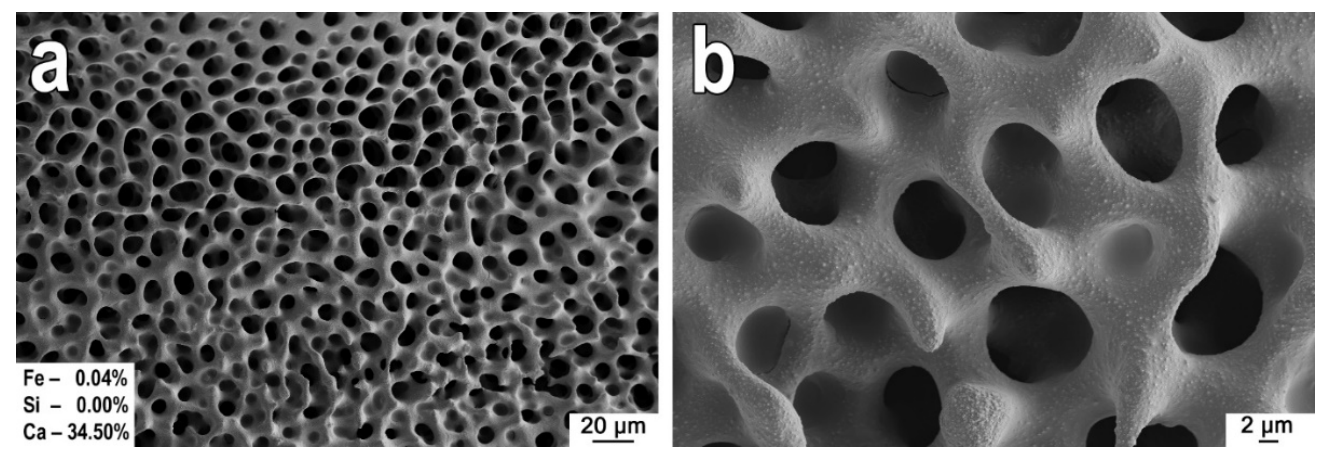

Figure 3. (a,b) SEM images of the skeleton of the sea urchin Strongylocentrotus intermedius without spines.

Considering that the sea urchin skeleton is covered with an organosilicon film, increasing the surface wettability with organosiloxane and allowing it to penetrate the capillaries, we decided to obtain a structured material with the use of the sea urchin test as a template and PFPS as a filler. Its decomposition property determines the choice of an iron-containing organosilicon polymer at high temperatures with the formation of a composite material containing silicon dioxide $\mathrm{SiO}_{2}$, which has high sorption properties, and iron oxide $\mathrm{Fe}_{2} \mathrm{O}_{3}$, which imparts magnetic properties to materials. Thus, the treatment of the sea urchin shell (template) with PFPS, followed by acid etching of the inorganic framework, leads to the formation of a polymer with a three-dimensional structure (Figure 4a). This structure is an inverted internal structure of the original sea urchin skeleton (Figure 3). 


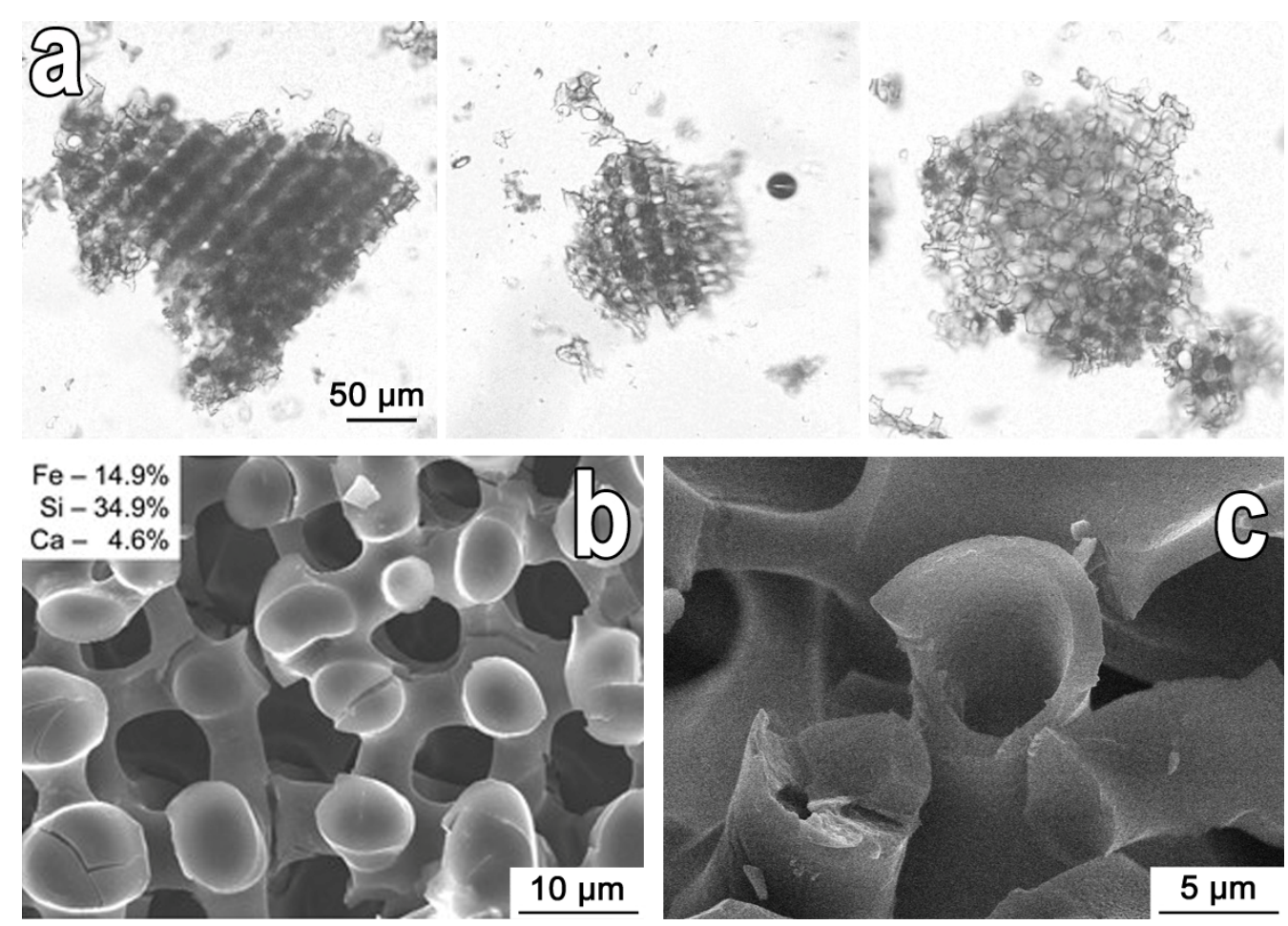

Figure 4. Images of the structure of a material that is polyferrophenyl-siloxane after the dissolution of the skeleton: (a) optical range, (b) micrometer range, (c) nanometer range.

The high magnification of SEM images reveals that the resulting polymer material has a hollow fiber structure, as seen in Figure 4c. This type of structure formed because of the evaporation of toluene from the PFPS solution into the internal volume of the framework with the release of PFPS on the channel surface. A decrease in the volume of the solution leads to the formation of a tubular structure.

According to SEM data, the structure of the PFPS composite (sample "c-PFPS") after its thermal treatment at $1000^{\circ} \mathrm{C}$ (sample "c-PFPS $/ 1000$ ") undergoes a significant change in comparison with the structure of the initial test (Figure 3) and partially destroyed (Figure $5 a, a^{*}$ ). When zooming in, it can be seen that the ceramic frame of the composite has a granular densely packed structure (Figure $5 b, b^{*}$ ). Additional acid treatment of this sample (sample "c-PFPS/1000/ $\mathrm{HCl}^{\prime}$ ) also leads to distortion of the structure of the ceramic framework, where the porous channels are significantly narrowed, and the grains forming its base have a melted shape (Figure $5 b, b^{*}$ ).

The results of the EDX analysis (Figure 5) show that the main qualitative composition of the composites does not change after heat treatment and acid etching. However, the quantitative content of elements in the samples is different. Treatment of the composite calcined at $1000{ }^{\circ} \mathrm{C}$ (sample "c-PFPS $/ 1000$ ") with hydrochloric acid (sample "c-PFPS $/ 1000 / \mathrm{HCl}^{\prime}$ ) leads to a significant decrease in the Ca content from 31.64 to $1.42 \mathrm{wt} \%$ (Figure 5); this decrease is associated with the acidic dissolution of calcium and magnesium silicate.

The mercury porosimetry data revealed that the original sea urchin shell treated with PFPS has a macroporous structure, with a pore size in the range of 5-50 $\mu \mathrm{m}$, and an average distribution in the region of $10 \mu \mathrm{m}$, as shown in the intrusion curves (Figure $6 \mathrm{a}, \mathrm{a}^{*}$ ). Calcination of this composite at $1000^{\circ} \mathrm{C}$ in the air did not lead to a significant change in the character of the intrusion curve; thus, the pattern of structural macroporosity of the sample in the range of the average pore size was the same before and after calcination (Figure $6 b, b^{*}$ ), which was also noted on the SEM image (Figure $5 a$ ). A visible difference was the pore volume, which increased threefold, and the size range of all available pores expanded from $500 \mathrm{~nm}$ to $100 \mu \mathrm{m}$; this was associated with the partial destruction of the porous framework and the formation of macro and micro defects in the structure, as also 
shown on the SEM image (Figure 5a*). Acid treatment led to a significant change in the structure of the sample, namely, its destruction. The pattern of the intrusion curve changed significantly. There was no more narrow pore size distribution (Figure 6c) because of the destruction of the porous framework, as shown in the SEM image (Figure 5b, $b^{*}$ ). The differential curve of mercury intrusion (Figure $6 c^{*}$ ) shows that the main porous volume lies in the range above $100 \mu \mathrm{m}$, which indicates the destruction of the material into large fragments after acid treatment.
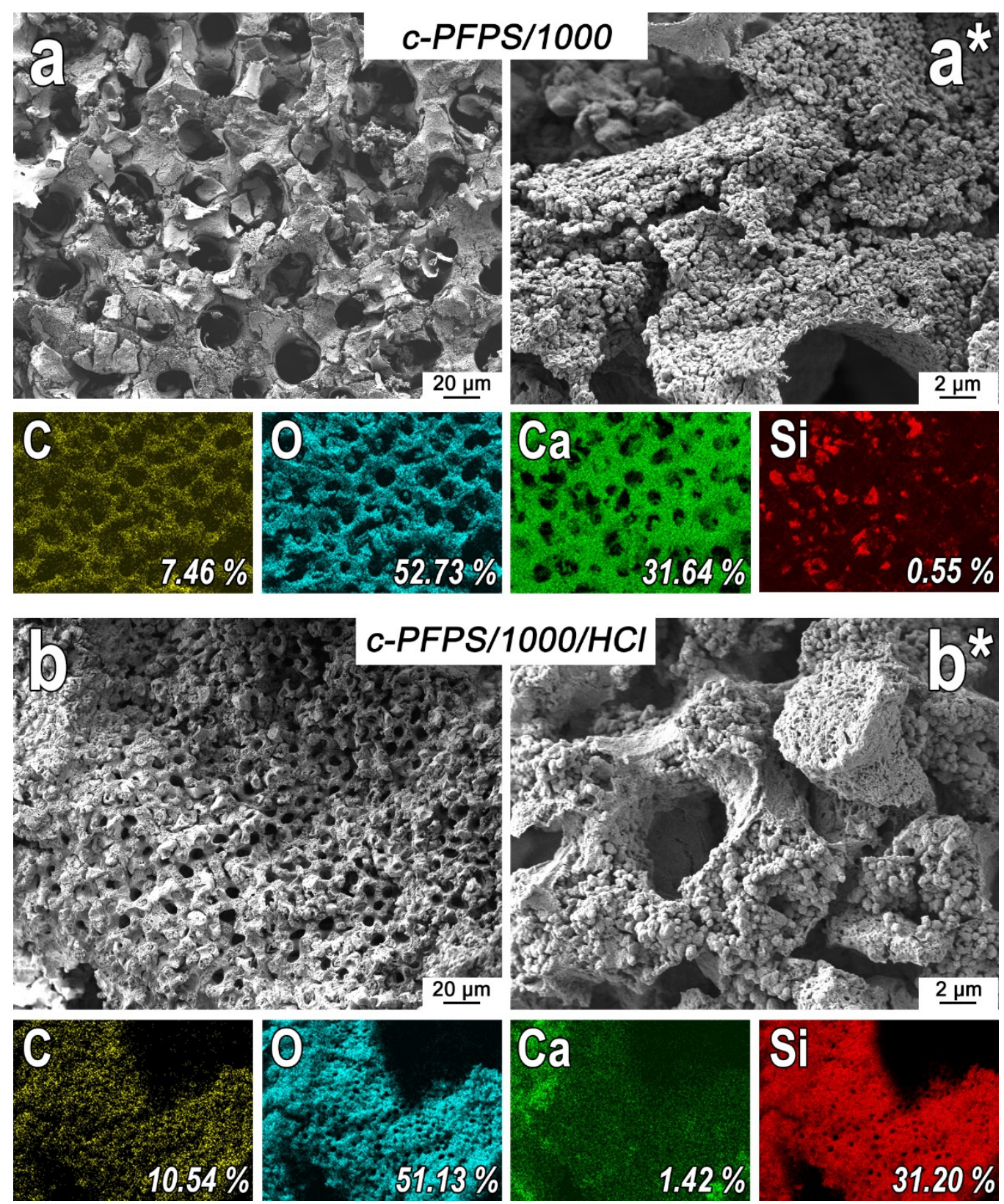

Figure 5. SEM images and EDX analysis (wt $\%)$ of PFPS composite samples: $\left(\mathbf{a}, \mathbf{a}^{*}\right)$-calcination at $1000{ }^{\circ} \mathrm{C}$ in the air (sample No. 2 of Table 1$) ;\left(\mathbf{b}, \mathbf{b}^{*}\right)$ - calcination at $1000{ }^{\circ} \mathrm{C}$ in air, followed by treatment with $\mathrm{HCl}$ (Table 1, sample No. 3). 

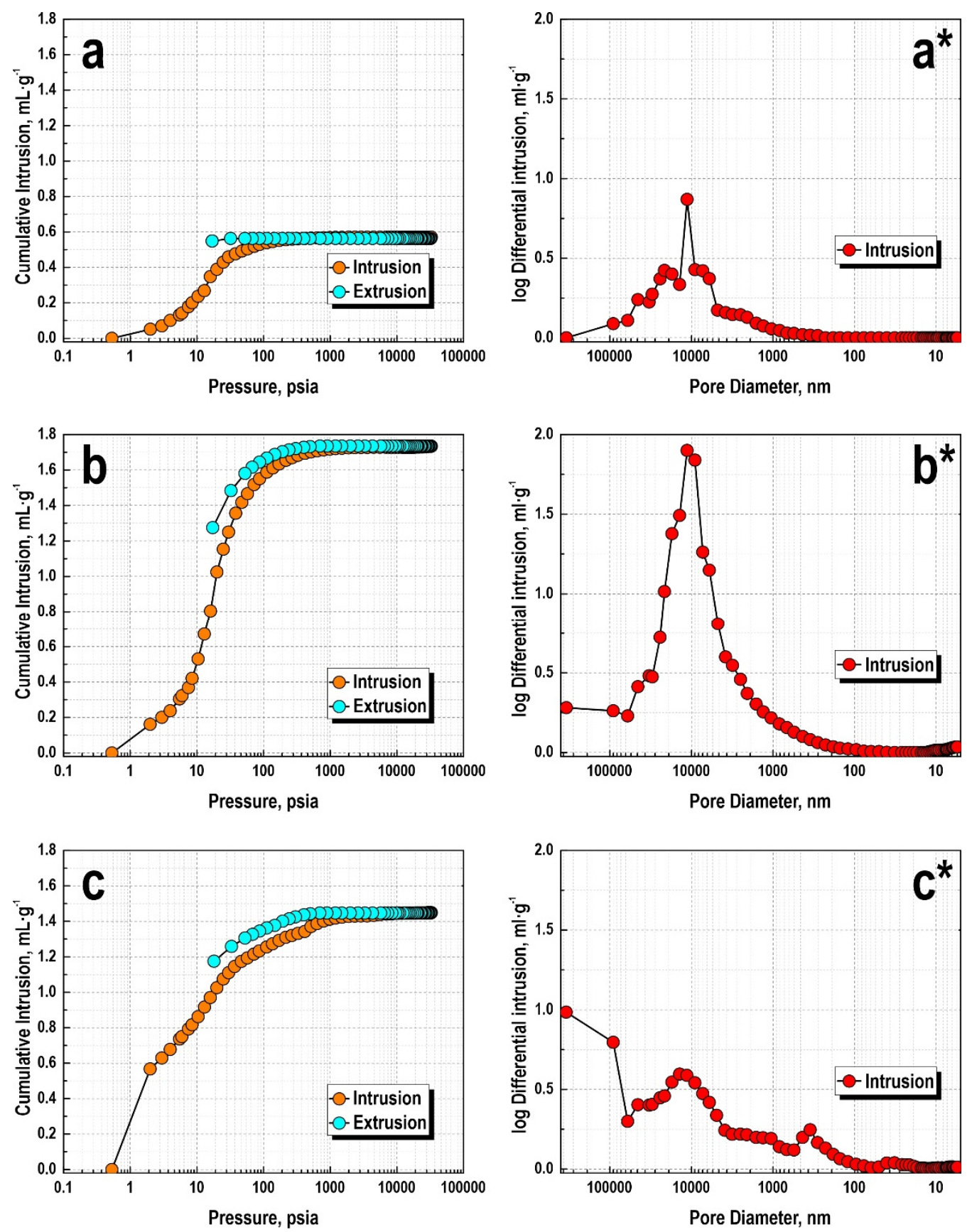

Figure 6. General and differential dependences of mercury intrusion into samples: $\left(\mathbf{a}, \mathbf{a}^{*}\right)$ - the original skeleton of the sea urchin Strongylocentrotus intermedius; $\left(\mathbf{b}, \mathbf{b}^{*}\right)$-PFPS composite calcined at $1000{ }^{\circ} \mathrm{C}$ (sample "c-PFPS/1000); (c, $\left.\mathrm{c}^{*}\right)$ — composite treated with $\mathrm{HCl}$ after calcination (sample "c-PFPS $/ 1000 / \mathrm{HCl}^{\prime \prime}$.

\section{Conclusions}

The paper investigates a method for template synthesis of porous biomimetic composites by a chemical interaction of PFPS with the sea urchin skeleton used as a pore-forming template. The study has shown that treatment of the porous sea urchin skeleton with PFPS used as a filler followed by removal of PFPS by acid etching resulted in formation of an organosilicon material with the structure inverted relative to the initial skeleton. An optical microscopy analysis established a linearly organized regular structure with a structured movement of about $20 \mu \mathrm{m}$. According to the EDX data, it was found that calcination of the sea urchin skeleton soaked with PFPS at $1000^{\circ} \mathrm{C}$ made it possible to form a ceramic composite based on calcium silicate and magnesium with a macroporous structure with an 
average pore size distribution of about $10 \mu \mathrm{m}$; this corresponds to the average pore size of the original sea urchin shell. SEM analysis and mercury porosimetry data determined that calcination leads to a threefold increase in the porous volume and an expansion of the range of all available pores from $500 \mathrm{~nm}$ to $100 \mu \mathrm{m}$, because of partial destruction of the framework and the formation of macro and micro defects in the structure. At the same time, we found that additional treatment of this composite with hydrochloric acid leads to a significant destruction of the porous structure caused by the dissolution and destruction of the silicate framework. Thus, the results of our study show that the original presented template synthesis method is promising and can be applied for the subsequent development of orderly porous biomimetics for practical purposes with the use of various polyorganosiloxanes of the sea urchin skeleton as a natural framework-forming template. However, it should be considered that the method of acid treatment is suitable for obtaining a silicone-organic composite with the inverted structure and not suitable for the formation of ceramic composite because it leads to melting of the template (sea urchin skeleton) without preserving the inorganic skeleton. In the second case, oxidative calcination is more suitable for the formation of ceramics. Varying the composition of organosiloxanes when processing the sea urchin skeleton will allow control of the composition of the final ceramics, and optimal modes of heat treatment will preserve the defect-free porous structure of the obtained final composites.

Author Contributions: Conceptualization, N.P.S.; validation, A.L.D.; formal analysis, I.G.K.; investigation, N.P.S., V.Y.M., N.V.M.; data curation, A.E.P., E.K.P.; writing-review and editing, A.E.P., E.K.P.; visualization, I.Y.B.; project administration, A.E.P. All authors have read and agreed to the published version of the manuscript.

Funding: The study was carried out with financial support from the State Assignment of the Ministry of Science and Higher Education of the Russian Federation, topic No. 00657-2020-0006. The equipment of the Joint Center for Collective Use, the interdisciplinary center in the field of nanotechnology and new functional materials of the Far Eastern Federal University and the Laboratory of Nuclear Technologies of the Far Eastern Federal University (FEFU, Vladivostok, Russia) were used in the study. The analysis of porosity by the method of mercury porosimetry was carried out on the equipment of the Institute of Chemistry, Far Eastern Branch of the Russian Academy of Sciences (IC FEB RAS, Vladivostok, Russia) financed from a grant from the Russian Science Foundation, project No. 18-73-10107 (budget article "overhead costs").

Institutional Review Board Statement: The study did not involve humans or animals.

Informed Consent Statement: Not applicable.

Data Availability Statement: Not applicable.

Acknowledgments: The authors are grateful to Mayorov V. Yu. of the Laboratory of Sorption Processes and the Laboratory of Composite and Ceramic Functional Materials of the Institute of Chemistry (FEB RAS) for analyzing the porosity of three experimental samples.

Conflicts of Interest: The authors declare no conflict of interest.

\section{References}

1. Martín-Palma, R.J; Kolle, M. Biomimetic photonic structures for optical sensing. Opt. Laser Technol. 2019, 109, 270-277. [CrossRef]

2. Romanholo, P.V.V.; Razzino, C.A.; Raymundo-Pereira, P.A.; Prado, T.M.; Machado, S.A.S.; Sgobbi, L.F. Biomimetic electrochemical sensors: New horizons and challenges in biosensing applications. Biosens. Bioelectron. 2021, 185, 113242. [CrossRef]

3. Zhao, L.; Yang, H.; He, F.; Yao, Y.; Xu, R.; Wang, L.; He, L.; Zhang, H.; Li, S.; Huang, F. Biomimetic N-doped sea-urchinstructured porous carbon for the anode material of high-energy-density potassium-ion batteries. Electrochim. Acta 2021, 388, 138565. [CrossRef]

4. Han, X.; Wu, J.; Zhang, X.; Shi, J.; Wei, J.; Yang, Y.; Wu, B.; Feng, Y. Special issue on advanced corrosion-resistance materials and emerging applications. The progress on antifouling organic coating: From biocide to biomimetic surface. J. Mater. Sci. Technol. 2021, 61, 46-62. [CrossRef]

5. Li, W.; Pei, Y.; Zhang, C.; Kottapalli, A.G.P. Bioinspired designs and biomimetic applications of triboelectric nanogenerators. Nano Energy 2021, 84, 105865. [CrossRef] 
6. Al-Ketan, O.; Rowshan, R.; Alami, A.H. Biomimetic Materials for Engineering Applications. In Reference Module in Materials Science and Materials Engineering; Elsevier: Amsterdam, The Netherlands, 2020.

7. Cojocaru, F.D.; Balan, V.; Tanase, C.E.; Popa, I.M.; Butnaru, M.; Bredetean, O.; Mares, M.; Nastasa, V.; Pasca, S.; Verestiuc, L. Development and characterisation of microporous biomimetic scaffolds loaded with magnetic nanoparticles as bone repairing material. Ceram. Int. 2021, 47, 11209-11219. [CrossRef]

8. Cruz, E.; Hubert, T.; Chancoco, G.; Naim, O.; Chayaamor-Heil, N.; Cornette, R.; Badarnah, L.; Raskin, K.; Aujard, F. Design processes and multi-regulation of biomimetic building skins: A comparative analysis. Energy Build. 2021, 246, 111034. [CrossRef]

9. Wang, R.; Yan, H.; Yu, A.; Ye, L.; Zhai, G. Cancer targeted biomimetic drug delivery system. J. Drug Deliv. Sci. Technol. 2021, 63, 102530. [CrossRef]

10. Baldino, L.; Aragón, J.; Mendoza, G.; Irusta, S.; Cardea, S.; Reverchon, E. Production, characterization and testing of antibacterial PVA membranes loaded with $\mathrm{HA}-\mathrm{Ag}_{3} \mathrm{PO}_{4}$ nanoparticles, produced by SC-CO 2 phase inversion. J. Chem. Technol. Biotechnol. 2019, 94, 98-108. [CrossRef]

11. Ajmal, G.; Bonde, G.V.; Mittal, P.; Khan, G.; Pandey, V.K.; Bakade, B.V.; Mishra, B. Biomimetic PCL-gelatin based nanofibers loaded with ciprofloxacin hydrochloride and quercetin: A potential antibacterial and anti-oxidant dressing material for accelerated healing of a full thickness wound. Int. J. Pharm. 2019, 567, 118480. [CrossRef]

12. Fuwad, A.; Ryu, H.; Malmstadt, N.; Kim, S.M.; Jeon, T.J. Biomimetic membranes as potential tools for water purification: Preceding and future avenues. Desalination 2019, 458, 97-115. [CrossRef]

13. Chen, W.; Mo, J.; Du, X.; Zhang, Z.; Zhang, W. Biomimetic dynamic membrane for aquatic dye removal. Water Res. 2019, 151, 243-251. [CrossRef]

14. Liu, H.; Liu, L.; Yu, J.; Yin, X.; Ding, B. High-efficiency and super-breathable air filters based on biomimetic ultrathin nanofiber networks. Compos. Commun. 2020, 22, 100493. [CrossRef]

15. Jakšić, Z.; Jakšić, O. Biomimetic nanomembranes: An overview. Biomimetics 2020, 5, 24. [CrossRef] [PubMed]

16. Tu, Y.M.; Samineni, L.; Ren, T.; Schantz, A.B.; Song, W.; Sharma, S.; Kumar, M. Prospective applications of nanometer-scale pore size biomimetic and bioinspired membranes. J. Memb. Sci. 2021, 620, 118968. [CrossRef]

17. Park, C.W.; Lee, J.H.; Seo, J.K.; Ran, W.T.A.; Whang, D.; Hwang, S.M.; Kim, Y.J. Graphene/pvdf composites for ni-rich oxide cathodes toward high-energy density li-ion batteries. Materials 2021, 14, 2271. [CrossRef]

18. Kamedulski, P.; Lukaszewicz, J.P.; Witczak, L.; Szroeder, P.; Ziolkowski, P. The importance of structural factors for the electrochemical performance of graphene/carbon nanotube/melamine powders towards the catalytic activity of oxygen reduction reaction. Materials 2021, 14, 2448. [CrossRef] [PubMed]

19. Chae, G.S.; Youn, D.H.; Lee, J.S. Nanostructured iron sulfide/n, s dual-doped carbon nanotube-graphene composites as efficient electrocatalysts for oxygen reduction reaction. Materials 2021, 14, 2146. [CrossRef] [PubMed]

20. Hu, M.L.; Masoomi, M.Y.; Morsali, A. Template strategies with MOFs. Coord. Chem. Rev. 2019, 387, 415-435. [CrossRef]

21. Wang, C.Y.; Jiao, K.; Yan, J.F.; Wan, M.C.; Wan, Q.Q.; Breschi, L.; Chen, J.H.; Tay, F.R.; Niu, L.N. Biological and synthetic template-directed syntheses of mineralized hybrid and inorganic materials. Prog. Mater. Sci. 2021, 116, 100712. [CrossRef]

22. Yang, T.; Wu, Z.; Chen, H.; Zhu, Y.; Li, L. Quantitative 3D structural analysis of the cellular microstructure of sea urchin spines (I): Methodology. Acta Biomater. 2020, 107, 204-217. [CrossRef] [PubMed]

23. Shapkin, N.P.; Khalchenko, I.G.; Panasenko, A.E.; Drozdov, A.L. Sea urchin skeleton: Structure, composition, and application as a template for biomimetic materials. In Proceedings of the AIP Conference Proceedings, St. Petersburg, Russia, 19-21 May 2017; Volume 1858, p. 020006. [CrossRef]

24. Donnay, G.; Pawson, D.L. X-ray Diffraction Studies of Echinoderm Plates. Science 1969, 166, 1147-1150. [CrossRef] [PubMed]

25. Weber, J.N. The incorporation of magnesium into the skeletal calcites of echinoderms. Am. J. Sci. 1969, 267, 537-566. [CrossRef]

26. Voronkov, M.G.; Shapkin, N.P. Phosphorus-containing polymetalloorganosiloxanes. J. Organomet. Chem. 1990, 389, 169-186. [CrossRef] 